
\title{
$\angle S$ Research Suare \\ Refracture of the Cemented Vertebrae after Percutaneous Vertebroplasty: Risk Factors and Imaging Findings
}

\section{Yu-chao Xiong}

Guangzhou Red Cross Hospital

\section{Wei Guo}

Wuhan Third Hosipital囚Tongren Hosipital of Wuhan university

\section{Fan Xu}

Guangzhou Red Cross Hospital

Ci-ci Zhang

Guangzhou Red Cross Hospital

\section{Zhi-ping Liang}

Guangzhou Red Cross Hospital

\section{Li Wu}

Guangzhou Red Cross Hospital

\section{Song Chen}

Guangzhou Red Cross Hospital

Xu-wen Zeng ( $\sim$ gzshszhyyfsk@163.com )

Guangzhou Red Cross Hospital https://orcid.org/0000-0003-1971-6036

\section{Research article}

Keywords: vertebroplasty, Risk Factors, Magnetic Resonance Imaging, Spinal Fractures, Bone Cements

Posted Date: February 17th, 2021

DOI: https://doi.org/10.21203/rs.3.rs-241616/v1

License: (1) (1) This work is licensed under a Creative Commons Attribution 4.0 International License. Read Full License 


\section{Abstract}

Background: To determine the related imaging findings and risk factors to refracture of the cemented vertebrae after percutaneous vertebroplasty (PVP) treatment.

Methods: Patients who were treated with PVP for single vertebral compression fractures (VCFs) and met this study's inclusion criteria were retrospectively reviewed from January 2012 to January 2019. The follow-up period was at least 2 years. Forty-eight patients with refracture of the cemented vertebrae and 45 non-refractured patients were included. The following variates were reviewed: age, sex, fracture location, bone mineral density (BMD), intravertebral cleft (IVC), kyphotic angle (KA), wedge angle, endplate cortical disruption, cement volume, surgical approach, non-PMMA-endplate-contact (NPEC), cement leakage, other vertebral fractures, reduction rate (RR), and reduction angle (RA). Multiple logistic regression modeling was used to identify the independent risk factors of refracture.

Results. Refracture was found in $48(51.6 \%)$ patients. Four risk factors, including IVC ( $P=0.005)$, endplate cortical disruption $(P=0.037)$, larger RR $(P=0.007)$, and NPEC $(P=0.006)$ were found to be significant independent risk factors for refracture.

Conclusions: Patients with IVC or larger RR, NPEC, or endplate cortical disruption have a high risk of refracture in the cemented vertebrae after PVP.

\section{Background}

Percutaneous vertebroplasty (PVP) is a minimally invasive technique for the treatment of vertebral compression fractures (VCFs). Most clinical studies [1-5] have reported that this treatment can provide immediate pain relief and biomechanical stability, and restore partial vertebral height. Despite these excellent clinical results, complications such as cement leakage, infection, embolism, fractures in the adjacent vertebrae, and refracture of previously treated vertebrae have been reported [6-10]. However, recompression in cemented vertebrae may lead to aggravation of the kyphotic deformity, vertebral height loss, and even compression of the spinal cord by vertebral body fracture, which usually requires further treatment $[8,9]$. Some researchers $[8,11,12]$ believe that cement distribution patterns may be an important predisposing factor to refracture. Kim [13] reported that the intravertebral cleft (IVC) might be a significant risk factor. Although research has highlighted many risk factors, refracture of the cemented vertebrae remains a controversial topic.

The treatment of refracture in cemented vertebrae remains challenging. The treatment strategy for vertebral fractures need to be changed when the risks of PVP outweighs the efficacy. Thus, the purpose of this study was to assess the related imaging findings and risk factors of patients who experienced refracture of the cemented vertebrae after PVP.

\section{Methods}




\section{Patient selection}

This retrospective cohort study was conducted from January 1, 2012 to January 1, 2019 in the spine surgery department of our hospital. The research program was approved by Institutional Review Board of Guangzhou Red Cross Hospital, and all procedures were performed according to the Declaration of Helsinki. All patients received written informed consent before operation.

A total of 1303 patients who were diagnosed with VCF (T4-L5) receiving single level PVP were enrolled in this study. Patients who met the following criteria were excluded:

1. pathological vertebral fractures secondary to tumor, severe inflammation, or long-term corticosteroid use;

2. patients without available radiographs or magnetic resonance imaging (MRI);

3. No history of PVP surgery;

4. patients with neurologic deficits;

5. follow-up time less than 24 months;

6. patients with hyperparathyroidism, hyperthyroidism, or other bone metabolic diseases

The inclusion criteria were as follows:

1. patients who had plain films preoperatively, immediately after surgery, and at the final follow-up;

2. patients who underwent MRI preoperatively and at last follow-up;

3. follow-up period of at least two years;

4. patients with a bone density scan before the PVP;

5. single-level symptomatic VCF treated with PVP;

Based on these criteria, a total of 93 patients were enrolled in our study (75 women, 18 men).

\section{Operative procedure}

All patients received bilateral or unilateral PVP in the prone position under the guidance of C-arm fluoroscopy after local anesthesia (1\% lidocaine). According to Jensen's technique [14], under C-arm fluoroscopic control, 11-gauge or 13-gauge bone biopsy needles were entered the pedicle in a slightly descending manner or parallel to the superior and inferior edges of the pedicle. The needle was positioned in the optimal position as confirmed by $\mathrm{C}$-arm, that is, the tip reached the anterior third of the vertebral body and the middle height of the midline.After the stylet was removed from the trocar, a formulated polymethylmethacrylate (PMMA) mixture was instilled, filling the fractured bone. The cement injection process was performed slowly, and strictly monitored under C-arm fluoroscopy in the lateral plane to avoid cement leakage. The bone cement filled the fractured vertebrae in the anterior third of the vertebral body as much as possible to form an effective mechanical column. The injection was immediately stopped when cement leakage was seen in the segmental vein, adjacent intervertebral disk, epidural space, or epidural vein. After PVP, all patients were allowed to ambulate the day after surgery. 
All images were analyzed during a time span of two weeks. Images were randomly evaluated by two experienced musculoskeletal radiologists in a random order, each blinded to the clinical information. A consensus was reached when two observers disagreed on the first reading. Face-to-face training was conducted before the study.

Analysis of pre-procedural images

All patients underwent MRI (sagittal T1WI, sagittal T2WI, and sagittal STIR) and anteroposterior and lateral radiographs of the spine prone position before the PVP. The anatomical locations of the involved vertebrae were divided into two groups: vertebrae outside the thoracolumbar junction (from T4 to T9 or L3 to L5) and vertebrae at the thoracolumbar junction (from T10 to L2) [15]. The IVC was detected as an area of signal loss (gas-containing space) or showing marked hyperintensity (fluid collection) on sagittal T2-weighted images $[15,16]$. Endplate cortical disruption was determined as evident discontinuation in the cortical endplate as seen on sagittal T2/T1-weighted images [17]. The kyphotic angle (KA) (Cobb's angle) was defined as the angle between the upper endplate of the upper vertebra and the lower endplate of the lower vertebra. At L5, the KA was defined as the angle between the upper endplate of L4 and the upper endplate of the sacral vertebra. Wedge angle (WA) was defined as the angle between the upper endplate line and the lower endplate of the fractured vertebra. Vertebral height was measured at the maximum compression point of the fractured vertebrae. Vertebral compression rate (CR) refers to the ratio of vertebral height of the fractured vertebrae to the average vertebral height of the upper and lower vertebrae at the same site [18]. At L5, CR was the ratio of L4 vertebral height to L5 vertebral height at the same site.

Analysis of images during PVP or within two weeks after PVP

All patients underwent anteroposterior and lateral radiographs of the spine prone position during PVP or within two weeks after PVP. Cement leakage was defined as any cement present in the space beyond the cortical margin [19]. Non-PMMA-Endplate-Contact (NPEC) was defined as postoperative plain radiographs showing that the injected PMMA did not come into contact with the upper and lower endplates [20]. The patterns of NPEC were classified as NPEC on the upper endplate, NPEC on the lower endplate, NPEC on the upper and lower endplates, and no NPEC on anteroposterior and lateral radiography of the treated vertebra [21]. Reduction rate (RR) was calculated as the difference between preoperative and immediate postoperative CR [18]. Reduction angle (RA) was calculated as the difference between preoperative and immediate postoperative KA [18].

Analysis of images with a follow-up time of more than two years

All patients underwent MRI (sagittal T1WI, sagittal T2WI and sagittal STIR) and anteroposterior and lateral radiographs of the spine prone position with a follow-up time of more than two years. 
Compression rate increase (CRI) was defined as the difference in CR between immediately after surgery and the last follow-up(Figure 1).

Patient demographics, including gender, age, interval (the period between the start of new back pain related to MRI-confirmed fracture and the time of PVP), other vertebral fractures, surgical approach, bone mineral density (BMD), and cement volume were also analyzed.

An evaluation of refracture of the cemented vertebrae

Two conditions had to be met to be considered a refracture of the cemented vertebrae: (1) Compression rate increase (CRI) $\geq 15 \%$ [18]; (2) Vertebral bone marrow edema at the final follow-up.

\section{Statistical analysis}

All statistical analyses were performed using statistics software (SPSS, Chicago, IL, USA). P $<0.05$ indicated a statistically significant difference. Logistic regression univariate and multivariate analyses were used to assess the risk factors for refracture of the cemented vertebrae after PVP. The possible risk factors with $P$ value less than or equal to 0.10 in univariate analysis were input into the final multivariate logistic regression model. After adjusting other risk factors, the significance of each risk factor on refracture was tested.

\section{Results}

In total, 93 patients (refracture group, $n=48$; non-refracture group, $n=45$ ) were reviewed. Patients in the refracture group were followed for 1.2-25.9 months (mean, 9.3 months; median, 11.2 months). In the refracture group, the CRI was $15.1-40.2 \%$ (mean, $23.87 \%$; standard deviation (SD), $7.89 \%$ ). Patients in the non-refracture group were followed for 24.8-46.6 months (mean, 33.2 months; median, 38.4 months).

Univariate analysis revealed that IVC $(P<0.001)$, endplate cortical disruption $(P=0.026)$, reduction rate $(P$ $<0.001)$, NPEC $(P<0.001)$, and kyphotic angle $(P=0.014)$ were significant factors for refracture of the cemented vertebrae after PVP (Table 1). On multivariate analysis, however, IVC ( $P=0.005$; odds ratio, 27.12; $95 \%$ confidence interval $[\mathrm{Cl}]$ : 2.67, 275.38), endplate cortical disruption ( $P=0.037$; odds ratio, 3.23; $95 \%$ confidence interval [Cl]: 1.07, 9.75), larger RR ( $P=0.007$; odds ratio, $2.94 ; 95 \%$ confidence interval [Cl]: $1.33,6.47)$, and NPEC ( $P=0.006$; odds ratio, $1.99 ; 95 \%$ confidence interval $[C l]: 1.23,3.24)$ showed significance after adjustment for other variables (Table 2 ). 
Table 1

Univariate analysis: clinical factors and imaging finds in the refracture and non-refracture groups

\begin{tabular}{|c|c|c|c|}
\hline clinical factors and imaging finds & Refracture(n = 48) & Non-refracture $(n=45)$ & $P$ value \\
\hline Age (years) & $79.65 \pm 7.90$ & $78.29 \pm 7.21$ & 0.303 \\
\hline Grender & & & 0.498 \\
\hline Men & 8 & 10 & \\
\hline Women & 40 & 35 & \\
\hline Fracture location & & & 0.215 \\
\hline Thoracolumbar & 33 & 36 & \\
\hline Non-thoracolumnar & 15 & 9 & \\
\hline $\operatorname{BMD}\left(\mathrm{g} / \mathrm{cm}^{2}\right)$ & $0.664 \pm 0.15$ & $0.73 \pm 0.16$ & 0.686 \\
\hline kyphotic angle $\left(^{\circ}\right)$ & $17.56 \pm 9.51$ & $12.58 \pm 9.64$ & 0.014 \\
\hline Wage angle $\left(^{\circ}\right)$ & $10.88 \pm 6.28$ & $10.20 \pm 5.01$ & 0.204 \\
\hline \multicolumn{4}{|l|}{ IVC } \\
\hline Present & 18 & 1 & 0 \\
\hline Absent & 30 & 44 & \\
\hline Endplate cortical disruption & & & 0.026 \\
\hline Present & 27 & 15 & \\
\hline Absent & 21 & 30 & \\
\hline Bone cement volume(ml) & $3.13 \pm 0.709$ & $3.01 \pm 0.663$ & 0.440 \\
\hline Surgical approach & & & 0.605 \\
\hline Left & 5 & 4 & \\
\hline Right & 38 & 39 & \\
\hline Bilateral & 5 & 2 & \\
\hline NEPC & & & 0 \\
\hline Present on lower endplate & 14 & 7 & \\
\hline Present on upper endplate & 7 & 10 & \\
\hline Present on upper and lower endplate & 26 & 16 & \\
\hline Absent & 1 & 12 & \\
\hline
\end{tabular}




\begin{tabular}{|llll|}
\hline clinical factors and imaging finds & Refracture $(\mathrm{n}=48)$ & Non-refracture $(\mathrm{n}=45)$ & P value \\
\hline Leakage of bone cement & & & 0.422 \\
Present & 13 & 9 & \\
Absent & 35 & 36 & 0.134 \\
other vertebral fractures & & 5 & \\
Adjacent vertebral fracture & 8 & 11 & \\
Non-adjacent vertebral fracture & 21 & 29 & 0 \\
No & 19 & $4.44 \pm 5.18$ & 0.491 \\
\hline Reduction rate $(\%)$ & $11.92 \pm 11.18$ & $4.76 \pm 6.28$ & \\
\hline Reduction angle $\left(^{\circ}\right)$ & $4.02 \pm 3.89$ & & \\
\hline
\end{tabular}

Table 2

Outcome of multivariate logistic regression analysis

\begin{tabular}{|lll|}
\hline & OR $(95 \% \mathrm{Cl})$ & $P$ value \\
\hline Endplate cortical disruption & $3.23(1.07-9.75)$ & 0.037 \\
\hline IVC & $27.12(2.67-275.38)$ & 0.005 \\
\hline RR (\%) & $2.94(1.33-6.47)$ & 0.007 \\
\hline NPEC & $1.99(1.23-3.24)$ & 0.006 \\
\hline
\end{tabular}

Table 3 shows the differences in displacement of the anterior edge of the vertebral body with and without endplate cortical disruption, illustrating a statistical difference.

Table 3

Association of displacement of the anterior edge and Endplate cortical disruption

\begin{tabular}{|llll|}
\hline & \multicolumn{2}{c|}{ Endplate cortical disruption } & \multirow{2}{*}{ P value } \\
\cline { 1 - 3 } & With(n= 42) & Without( $\mathrm{n}=51)$ & \\
\cline { 1 - 3 } displacement of the anterior edge $(\mathrm{mm})$ & $3.12 \pm 2.62$ & $1.67 \pm 2.18$ & 0.005 \\
\hline
\end{tabular}

\section{Discussion}

Researchers have not uniformly described the loss of vertebral height and the criteria for unified diagnosis of height loss in cemented vertebrae after PVP. He [12] and Kim [20] described 'recompression' of previously treated vertebrae. The term 'recompression' might be confused with additional loss of vertebral height, including osteoporosis [22]. Heo [9] and Yu [18] reported using recollapse to describe the loss of the same vertebrae after PVP. The term 'recollapse' might be misunderstood cement block cracked 
[12]. In the present study, there was vertebral bone marrow edema, and the loss of vertebral height only in the bony vertebra, not in the cement mass. For these reasons, we recommend using the term 'refracture' to describe this condition. In previous studies, recompression or refracture of augmented vertebrae were defined as a height reduction of $1 \mathrm{~mm}$ or $4 \mathrm{~mm}$ on follow-up radiographs $[12,23-25,20,15,26]$. Due to the magnification ratio on radiographs, the measurement of height loss can easily lead to incorrect evaluation. In addition, several long-term studies of patients who were post-vertebral augmentation have showed that in up to $30 \%$ of patients have a gradual decrease in vertebral body height of $10-15 \%$ after PVP between 12 and 24 months [27]. Thus, in this study, the criterion of 15\% decrease in height [18] and presence of vertebral bone marrow edema was adopted.

Although the risk factors for refracture in cemented vertebrae after PVP have been previously reported [8, $11]$, to our knowledge this is the first study to report the risk factors and imaging findings of refracture based on bone marrow edema as a diagnostic basis.

The incidence of refracture in cemented vertebrae was $3.68 \%(48 / 1303)$ in this study, which was approximately consistent with the findings in previous studies, which ranged from $0.56-27.63 \%[8,28,9$, $23,18]$. However, the author infers that the true incidence of refractures should be higher than the expected data in the present study. This is because some patients with refracture did not seeking medical services and the present study used rigorous inclusion and exclusion criteria and grouping criteria.

We evaluated the risk factors for refracture in cemented vertebrae. IVC showed a statistically significant relationship to refracture, which corresponds with many previous studies $[18,8,9,29,11,30]$. IVC is a risk factor for refracture in cemented vertebrae and can be explained by two factors; namely, the IVC factor and secondary changes caused by IVC.

With regard to the IVC factor, IVC provides radiological evidence of osteonecrosis [31, 28, 32]. Osteonecrosis of the involved vertebrae would progress after PVP, which would eventually weaken the structural rigidity of the vertebral body and result in refracture of the remainder of the vertebral body [9]. In addition, the fractured vertebrae with IVC was usually a solid lump cased volumetric pressure effect that may aggravate the process of osteonecrosis [9]. Heo et al. [9] also reported that the timing of PVP is of great importance for patients with IVC, given that it is likely unfavorable during the early phase of osteonecrosis. Premature PVP may cause collateral vessels in necrotic bone to fail to form.

With regard to secondary changes caused by the IVC factor, IVC was related to cement distribution pattern $[18,12,9]$ and vertebral height restoration [33].

When bone cement is injected, it often enters the low-pressure zone (IVC zone), which causes the bone cement to form solid lump cement, making it easier to form NPEC. In our study, the incidence of NPEC was significantly higher in patients with IVC $(94.74 \%)$ than without IVC $(78.38 \%)$. Further analysis also indicated that NPEC was a risk factor associated with refracture. Zhang [23] found that patients without NPEC had a lower risk of recompression compared with patients with NPEC on the upper and lower endplates. Hou [24] found that the smaller the distance between PMMA and the endplate, the lower the 
incidence of recompression. Heo [20] found that recompression occurred in unsupported areas of PMMA. Our findings are consistent with previous research. Bone cement is in contact with both the upper and lower endplates, so it can provide a better support in the vertical direction since the load is transmitted through both the upper and lower endplates, which are harder in nature. When bone cement had NPEC, the load did not transmitted through the cementless area, resulting in a stress shielding effect, so the bone cement may serve to concentrate stress on the surrounding fragile bones and lead to refracture.

In our study, compared with the VCFs without IVC, the height of the vertebral body with IVC increased from $7.19-12.63 \%$. Michael [33] also reported that vertebroplasty increased the height of the fractured vertebrae, and these effects were most remarkable in fractured vertebrae with IVC. Further analysis indicated that RR was a risk factor associated with refracture. Lin [11] also found that cemented vertebrae with significant vertebral height restoration after PVP were prone to refracture. Too much recovery of the vertebral body may lead to increased tension of the paravertebral soft tissue, which may lead to increased mechanical load on the enlarged vertebrae or more unstable fractures. Consequently, the risk of refracture of involved vertebrae increased with a greater degree of height restoration.

Overall, IVC affected RR and NPEC, but RR and IVC were not all dependent on the impact of IVC. The NPEC, IVC, and RR were independent risk factors for refracture in cemented vertebrae after PVP.

In our study, endplate cortical disruption was also an independent risk factor for refracture in cemented vertebrae after PVP. We explained the occurrence of refracture after PVP as a biomechanical model. When there is endplate cortical disruption, the anterior edge of the vertebral body will move forward in the process of bone cement injection (Table 3). Anterior vertebral displacement causes two consequences. On one hand, the axial force of the vertebral body will be partially dispersed laterally, and the vertebral body is weak against lateral pressure. On the other hand, the fractured vertebral body cannot be sufficiently filled with bone cement, because the displacement of the anterior edge of the vertebral body can offset the force of the bone cement to diffuse into the trabecular bone. As a result, the cemented vertebrae with endplate cortical disruption is more vulnerable to refracture.

Previous research found that BMD was a risk factor for refracture after surgery [34-36, 30]. However, in our study BMD was not a risk factor for refracture. We speculate that this is due to the fact that this study used bone marrow edema as a diagnostic criterion for refracture. Villarraga [36] found that the loss of height in cemented vertebrae was the natural development of osteoporosis concluded from finite element model analysis, so the loss of height in cemented vertebrae caused by osteoporosis may not cause bone marrow edema.

Although some studies [1-5] reported that PVP could provide significantly pain relief in patients with VCFs, more and more studies [37,38] does not support significant clinically benefits from PVP comparaed with placebo. Refarcture in cemented vertebrae may be one of the reasons why pain relief is not better than placebo. Based on these risk factors in our study, the future strategy for the treatment of pain caused by vertebral fractures may need to be changed. Conservative treatment seems to be more 
suitable for patients with risk factors. In our opinion, looking for strategies for poor clinical effects of PVP provides clinicians with a pragmatic method of how to best treat patients.

This study had several limitations. First, it was a retrospective study with a single center and relatively small sample size, and a prospective, multi-center studies with a larger sample size are required to ensure the universality of our conclusions. Second, two-dimensional X-ray was used to determine the NPEC. In these images, NPEC may be underestimated. To accurately assess NPEC, three-dimensional CT scans will help. Finally, although BMD showed no significant difference before the PVP, patients treated with more effective anti-osteoporotic agents may not respond the same to PVP.

\section{Conclusions}

Four independent risk factors were significantly associated with refracture of the cemented vertebrae after PVP, including intravertebral cleft, non-PMMA-endplate-contact, increased reduction rate, and endplate cortical disruption. Therefore, the current surgical methods and treatment strategies may need to be adjusted on the basis of the risk factors of patients.

\section{Abbreviations}

PVP percutaneous vertebroplasty

VCFs vertebral compression fractures

BMD bone mineral density

IVC intravertebral cleft

KA kyphotic angle

NPEC non-PMMA-endplate-contact

$\mathrm{RR}$ reduction rate

RA reduction angle

PMMA polymethylmethacrylate

MRI magnetic resonance imaging

WA wedge angle

CR compression rate

$\mathrm{CRI}$ compression rate increase 


\section{Declarations}

\section{Competing interests}

All authors declare that they have no competing interests.

\section{Funding}

No funding was obtained for this study.

\section{Availability of data and materials}

The datasets used and analyzed during the current study are available from the corresponding author on reasonable request.

\section{Ethics approval and consent to participate}

The study protocol was approved by Institutional Review Board of Guangzhou Red Cross Hospital, and all procedures were performed according to the Declaration of Helsinki. Written informed consent was obtained prospectively from all patients prior to surgery.

\section{Authors' contributions}

X.W.Z, Y.C.X and W.G were responsible for the study concept design, analysis and interpretation of data, drafting of the manuscript, and critical revision of the manuscript for intellectual content. X.W.Z, Y.C.X and F.X conducted data analyses and all the authors contributed to the interpretation of data. Z.P.L and S.C were responsible for the analysis and interpretation of data. L.W and C.C.Z conducted data collection and performed preliminary data preparations. All authors read and approved the final manuscript.

\section{Consent for publication}

Not applicable.

\section{Acknowledgment}

We thank Peter Mittwede, MD, PhD, from Liwen Bianji, Edanz Editing China (www.liwenbianji.cn/ac), for editing the English text of a draft of this manuscript.

\section{References}

1. Anderson PA, Froyshteter AB, Tontz WL Jr. Meta-analysis of vertebral augmentation compared with conservative treatment for osteoporotic spinal fractures. J Bone Miner Res. 2013;28(2):372-82. doi:10.1002/jbmr.1762. 
2. Clark W, Bird P, Gonski P, Diamond TH, Smerdely P, McNeil HP, Schlaphoff G, Bryant C, Barnes E, Gebski V. Safety and efficacy of vertebroplasty for acute painful osteoporotic fractures (VAPOUR): a multicentre, randomised, double-blind, placebo-controlled trial. Lancet. 2016;388(10052):1408-16. doi:10.1016/S0140-6736(16)31341-1.

3. De Leacy R. New, High-Quality Evidence for Vertebroplasty in the Management of Painful Recent Compression Fractures: Review of the VAPOUR Trial. World Neurosurg. 2016;96:596-8. doi:10.1016/j.wneu.2016.09.043.

4. Klazen CA, Lohle PN, de Vries J, Jansen FH, Tielbeek AV, Blonk MC, Venmans A, van Rooij WJ, Schoemaker MC, Juttmann JR, Lo TH, Verhaar HJ, van der Graaf Y, van Everdingen KJ, Muller AF, Elgersma OE, Halkema DR, Fransen H, Janssens X, Buskens E, Mali WP. Vertebroplasty versus conservative treatment in acute osteoporotic vertebral compression fractures (Vertos II): an openlabel randomised trial. Lancet. 2010;376(9746):1085-92. doi:10.1016/s0140-6736(10)60954-3.

5. Masala S, Mastrangeli R, Petrella MC, Massari F, Ursone A, Simonetti G. Percutaneous vertebroplasty in 1,253 levels: results and long-term effectiveness in a single centre. Eur Radiol. 2009;19(1):165-71. doi:10.1007/s00330-008-1133-4.

6. Kim YJ, Lee JW, Park KW, Yeom JS, Jeong HS, Park JM, Kang HS. Pulmonary cement embolism after percutaneous vertebroplasty in osteoporotic vertebral compression fractures: incidence, characteristics, and risk factors. Radiology. 2009;251(1):250-9. doi:10.1148/radiol.2511080854.

7. Schmid KE, Boszczyk BM, Bierschneider M, Zarfl A, Robert B, Jaksche H. Spondylitis following vertebroplasty: a case report. Eur Spine J. 2005;14(9):895-9. doi:10.1007/s00586-005-0905-7.

8. Kang SK, Lee CW, Park NK, Kang TW, Lim JW, Cha KY, Kim JH. Predictive risk factors for refracture after percutaneous vertebroplasty. Annals of rehabilitation medicine. 2011;35(6):844-51. doi:10.5535/arm.2011.35.6.844.

9. Heo DH, Chin DK, Yoon YS, Kuh SU. (2009) Recollapse of previous vertebral compression fracture after percutaneous vertebroplasty. Osteoporosis international: a journal established as result of cooperation between the European Foundation for Osteoporosis and the National Osteoporosis Foundation of the USA 20 (3):473-480. doi:10.1007/s00198-008-0682-3.

10. Suzuki N, Ogikubo O, Hansson T. Previous vertebral compression fractures add to the deterioration of the disability and quality of life after an acute compression fracture. Eur Spine J. 2010;19(4):56774. doi:10.1007/s00586-009-1162-y.

11. Lin WC, Lee YC, Lee CH, Kuo YL, Cheng YF, Lui CC, Cheng TT. Refractures in cemented vertebrae after percutaneous vertebroplasty: a retrospective analysis. European spine journal: official publication of the European Spine Society, the European Spinal Deformity Society, and the European Section of the Cervical. Spine Research Society. 2008;17(4):592-9. doi:10.1007/s00586-007-0564-y.

12. He D, Lou C, Yu W, Zhu K, Wu Z, Liu F, Chen M, Zheng L, Chen Z, Fan S. Cement Distribution Patterns Are Associated with Recompression in Cemented Vertebrae After Percutaneous Vertebroplasty: A Retrospective Study. World neurosurgery. 2018;120:e1-7. doi:10.1016/j.wneu.2018.06.113. 
13. Kim YJ, Lee JW, Kim KJ, Chung SK, Kim HJ, Park JM, Kang HS. Percutaneous vertebroplasty for intravertebral cleft: analysis of therapeutic effects and outcome predictors. Skeletal radiology. 2010;39(8):757-66. doi:10.1007/s00256-009-0866-8.

14. Jensen ME, Evans AJ, Mathis JM, Kallmes DF, Cloft HJ, Dion JE. Percutaneous polymethylmethacrylate vertebroplasty in the treatment of osteoporotic vertebral body compression fractures: technical aspects. AJNR Am J Neuroradiol. 1997;18(10):1897-904.

15. Lin WC, Lu CH, Chen HL, Wang HC, Yu CY, Wu RW, Cheng YF, Lui CC. The impact of preoperative magnetic resonance images on outcome of cemented vertebrae. European spine journal: official publication of the European Spine Society, the European Spinal Deformity Society, and the European Section of the Cervical. Spine Research Society. 2010;19(11):1899-906. doi:10.1007/s00586-0101434-6.

16. Wu AM, Chi YL, Ni WF. Vertebral compression fracture with intravertebral vacuum cleft sign: pathogenesis, image, and surgical intervention. Asian Spine J. 2013;7(2):148-55. doi:10.4184/asj.2013.7.2.148.

17. Hong SJ, Lee S, Yoon JS, Kim JH, Park YK. Analysis of intradiscal cement leakage during percutaneous vertebroplasty: multivariate study of risk factors emphasizing preoperative MR findings. Journal of neuroradiology Journal de neuroradiologie. 2014;41(3):195-201. doi:10.1016/j.neurad.2013.07.004.

18. Yu WB, Jiang XB, Liang D, Xu WX, Ye LQ, Wang J. (2019) Risk factors and score for recollapse of the augmented vertebrae after percutaneous vertebroplasty in osteoporotic vertebral compression fractures. Osteoporosis international: a journal established as result of cooperation between the European Foundation for Osteoporosis and the National Osteoporosis Foundation of the USA 30 (2):423-430. doi:10.1007/s00198-018-4754-8.

19. Gao C, Zong M, Wang WT, Xu L, Cao D, Zou YF. (2018) Analysis of risk factors causing short-term cement leakages and long-term complications after percutaneous kyphoplasty for osteoporotic vertebral compression fractures. Acta radiologica (Stockholm, Sweden: 1987) 59 (5):577-585. doi:10.1177/0284185117725368.

20. Kim YY, Rhyu KW. Recompression of vertebral body after balloon kyphoplasty for osteoporotic vertebral compression fracture. European spine journal: official publication of the European Spine Society, the European Spinal Deformity Society, and the European Section of the Cervical. Spine Research Society. 2010;19(11):1907-12. doi:10.1007/s00586-010-1479-6.

21. Oka M, Matsusako M, Kobayashi N, Uemura A, Numaguchi Y. Intravertebral cleft sign on fatsuppressed contrast-enhanced MR: correlation with cement distribution pattern on percutaneous vertebroplasty. Acad Radiol. 2005;12(8):992-9. doi:10.1016/j.acra.2005.05.003.

22. Liu JT, Li CS, Chang CS, Liao WJ. Long-term follow-up study of osteoporotic vertebral compression fracture treated using balloon kyphoplasty and vertebroplasty. J Neurosurg Spine. 2015;23(1):94-8. doi:10.3171/2014.11.SPINE14579. 
23. Zhang L, Wang Q, Wang L, Shen J, Zhang Q, Sun C. Bone cement distribution in the vertebral body affects chances of recompression after percutaneous vertebroplasty treatment in elderly patients with osteoporotic vertebral compression fractures. Clin Interv Aging. 2017;12:431-6. doi:10.2147/cia.S113240.

24. Hou Y, Yao Q, Zhang G, Ding L, Huang H. Polymethylmethacrylate distribution is associated with recompression after vertebroplasty or kyphoplasty for osteoporotic vertebral compression fractures: A retrospective study. PloS one. 2018;13(6):e0198407. doi:10.1371/journal.pone.0198407.

25. McKiernan F, Faciszewski T, Jensen R. Reporting height restoration in vertebral compression fractures. Spine (Phila Pa 1976). 2003;28(22):2517-21. doi:10.1097/01.BRS.0000092424.29886.C9. disucssion 2513.

26. Black DM, Cummings SR, Karpf DB, Cauley JA, Thompson DE, Nevitt MC, Bauer DC, Genant HK, Haskell WL, Marcus R, Ott SM, Torner JC, Quandt SA, Reiss TF, Ensrud KE. Randomised trial of effect of alendronate on risk of fracture in women with existing vertebral fractures. Fracture Intervention Trial Research Group Lancet. 1996;348(9041):1535-41. doi:10.1016/s0140-6736(96)07088-2.

27. Jacobson RE, Palea O, Granville M. Progression of Vertebral Compression Fractures After Previous Vertebral Augmentation: Technical Reasons for Recurrent Fractures in a Previously Treated Vertebra. Cureus. 2017;9(10):e1776. doi:10.7759/cureus.1776.

28. Chen LH, Hsieh MK, Liao JC, Lai PL, Niu CC, Fu TS, Tsai TT, Chen WJ. Repeated percutaneous vertebroplasty for refracture of cemented vertebrae. Arch Orthop Trauma Surg. 2011;131(7):927-33. doi:10.1007/s00402-010-1236-7.

29. Summa A, Crisi G, Cerasti D, Ventura E, Menozzi R, Ormitti F. Refractures in cemented vertebrae after percutaneous vertebroplasty and pain relief after a second procedure: a retrospective analysis. The neuroradiology journal. 2009;22(2):239-43. doi:10.1177/197140090902200216.

30. Li YX, Guo DQ, Zhang SC, Liang, Yuan K, Mo GY, Li DX, Guo HZ, Tang Y, Luo PJ. Risk factor analysis for re-collapse of cemented vertebrae after percutaneous vertebroplasty (PVP) or percutaneous kyphoplasty (PKP). International orthopaedics. 2018;42(9):2131-9. doi:10.1007/s00264-018-3838-6.

31. Dupuy DE, Palmer WE, Rosenthal DI. Vertebral fluid collection associated with vertebral collapse. AJR Am J Roentgenol. 1996;167(6):1535-8. doi:10.2214/ajr.167.6.8956592.

32. Naul LG, Peet GJ, Maupin WB. Avascular necrosis of the vertebral body: MR imaging. Radiology. 1989;172(1):219-22. doi:10.1148/radiology.172.1.2740507.

33. Teng MM, Wei CJ, Wei LC, Luo CB, Lirng JF, Chang FC, Liu CL, Chang CY. Kyphosis correction and height restoration effects of percutaneous vertebroplasty. AJNR Am J Neuroradiol. 2003;24(9):1893900.

34. Liebschner MA, Rosenberg WS, Keaveny TM. Effects of bone cement volume and distribution on vertebral stiffness after vertebroplasty. Spine (Phila Pa 1976). 2001;26(14):1547-54. doi:10.1097/00007632-200107150-00009.

35. Klazen CA, Venmans A, de Vries J, van Rooij WJ, Jansen FH, Blonk MC, Lohle PN, Juttmann JR, Buskens E, van Everdingen KJ, Muller A, Fransen H, Elgersma OE, Mali WP, Verhaar HJ. Percutaneous 
vertebroplasty is not a risk factor for new osteoporotic compression fractures: results from VERTOS II. AJNR Am J Neuroradiol. 2010;31(8):1447-50. doi:10.3174/ajnr.A2148.

36. Villarraga ML, Bellezza AJ, Harrigan TP, Cripton PA, Kurtz SM, Edidin AA. The biomechanical effects of kyphoplasty on treated and adjacent nontreated vertebral bodies. J Spinal Disord Tech. 2005;18(1):84-91. doi:10.1097/01.bsd.0000138694.56012.ce.

37. Buchbinder R, Johnston RV, Rischin KJ, Homik J, Jones CA, Golmohammadi K, Kallmes DF. Percutaneous vertebroplasty for osteoporotic vertebral compression fracture. Cochrane Database Syst Rev. 2018;4:CD006349. doi:10.1002/14651858.CD006349.pub3.

38. Firanescu CE, de Vries J, Lodder P, Venmans A, Schoemaker MC, Smeets AJ, Donga E, Juttmann JR, Klazen CAH, Elgersma OEH, Jansen FH, Tielbeek AV, Boukrab I, Schonenberg K, van Rooij WJJ, Hirsch JA, Lohle PNM. Vertebroplasty versus sham procedure for painful acute osteoporotic vertebral compression fractures (VERTOS IV): randomised sham controlled clinical trial. BMJ. 2018;361:k1551. doi:10.1136/bmj.k1551.

\section{Figures}

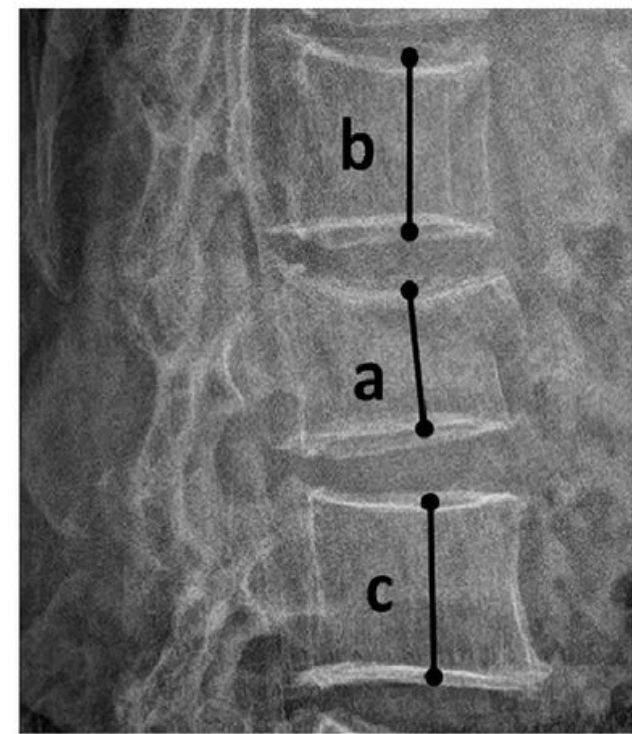

Pre-procedural lateral radiograph

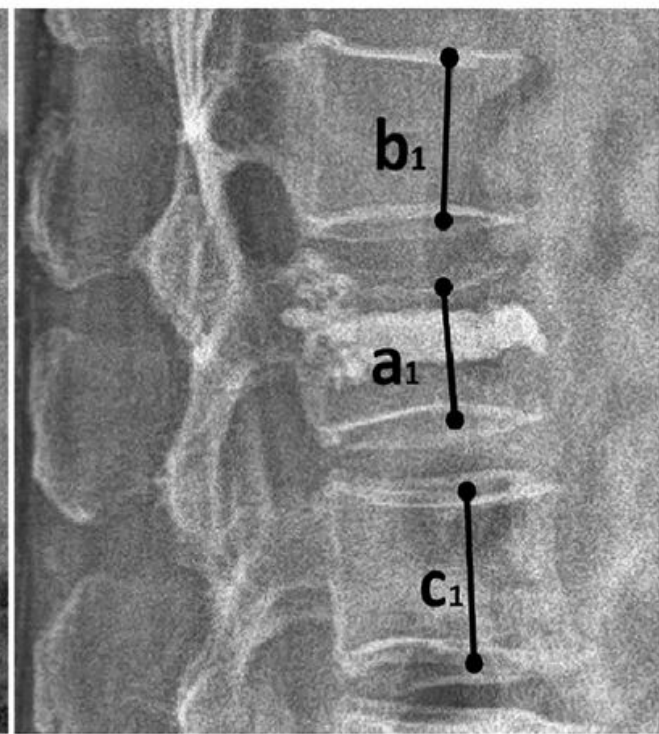

First postoperative lateral radiograph

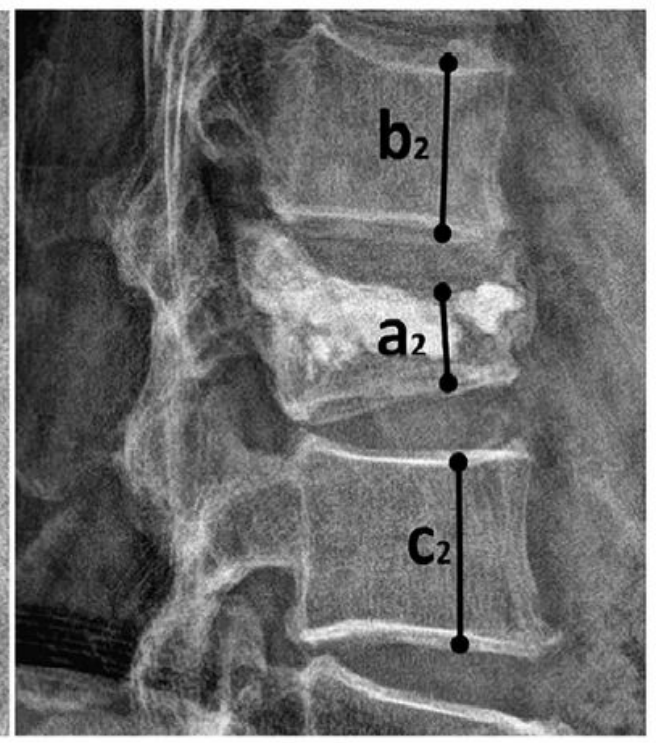

Last follow-up lateral radiograph

Reduction rate $(\mathrm{RR})=\left(\frac{2 \mathrm{a}}{\mathrm{b}+\mathrm{c}}-\frac{2 \mathrm{a} 1}{\mathbf{b}_{1}+\mathbf{c}_{1}}\right) \times 100 \%$ Compression rate increase $(\mathrm{CRI})=\left(\frac{2 \mathrm{a}_{1}}{\mathrm{~b}_{1}+\mathrm{c}_{1}}-\frac{2 \mathrm{a} 2}{\mathrm{~b}_{2}+\mathbf{c}_{2}}\right) \times 100 \%$

\section{Figure 1}

The reduction rate (RR) and compression rate increase (CRI) were calculated as above. 

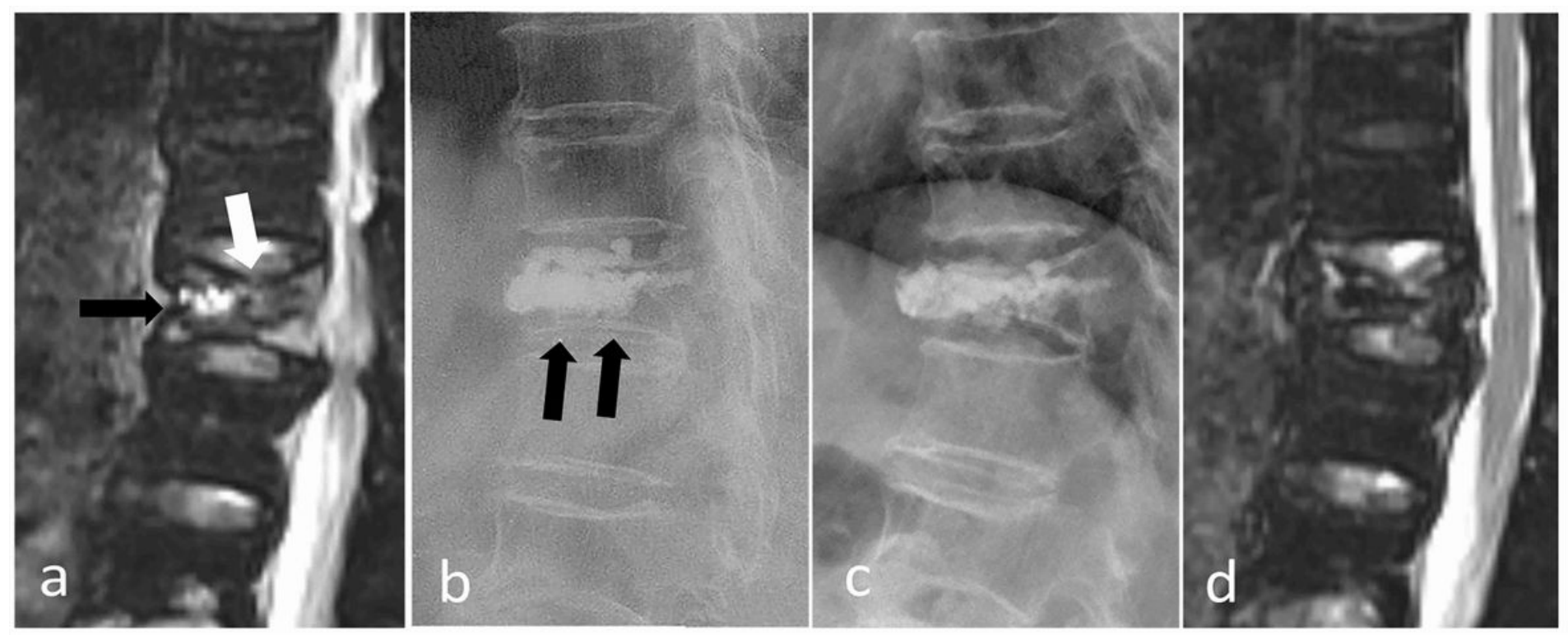

\section{Figure 2}

An 82-year-old woman with refracture after PVP MRI and lateral plain X-ray of an 82-year-old woman with a T11 compression fracture. (a) Sagittal STIR showed a T11 compression fracture with bone marrow edema, IVC (black arrow), and endplate cortical disruption (white arrow). (b) Postoperative X-ray showed the cemented vertebrae with NPEC on the lower endplate (black arrow). (c-d) MRI and lateral X-ray at five months after PVP showed loss of height of T11 and bone marrow edema. 

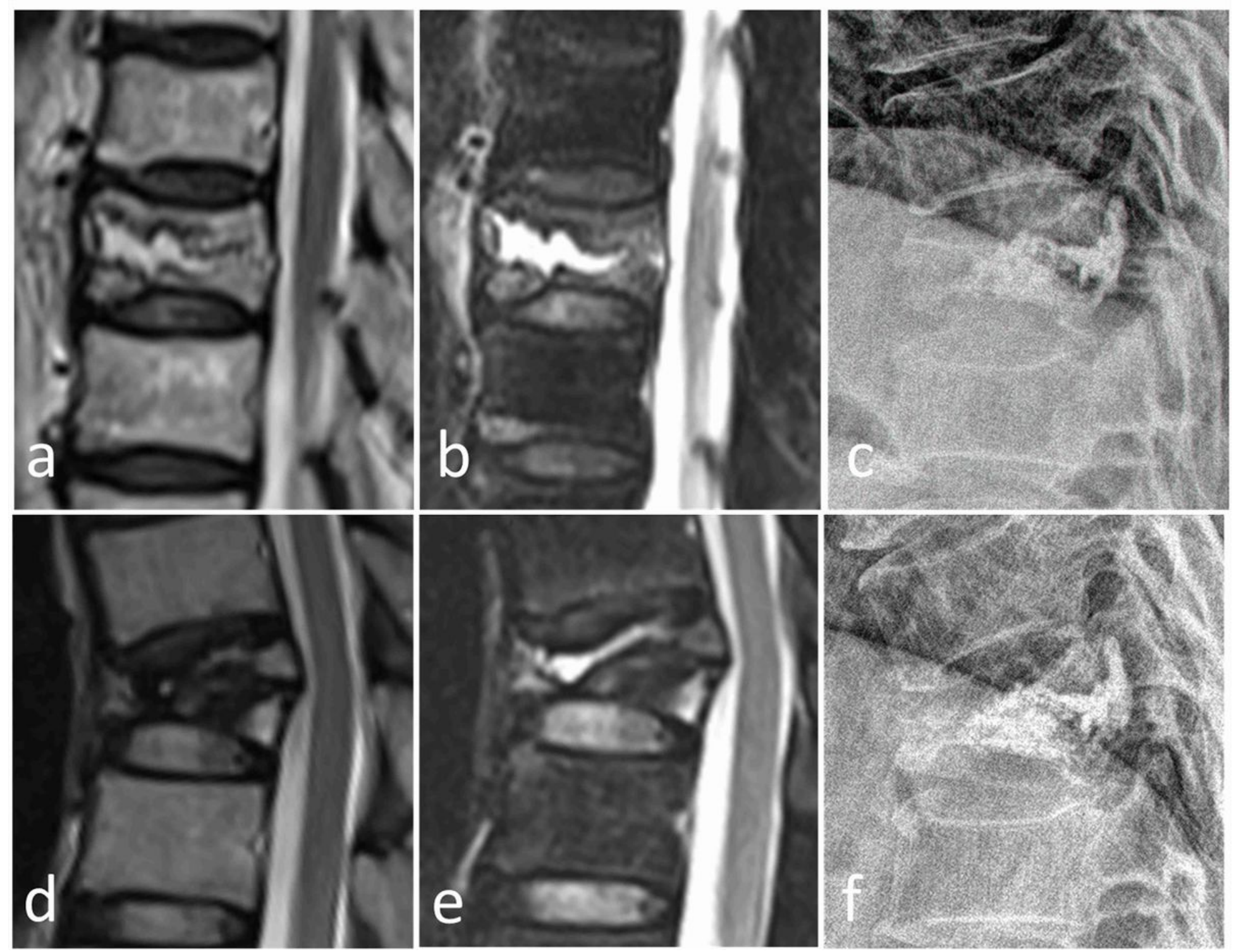

\section{Figure 3}

A 59-year-old man with refracture after PVP Preoperative T2W and STIR images $(a, b)$ showed a T10 compression fracture with IVC. Postoperative lateral radiographs (c) after two days showed NPEC on the lower and upper endplates. The T2WI, STIR image, and lateral radiograph five months after PVP (d-f) showed refracture of the cemented T10 vertebra with loss of height and bone marrow edema. 

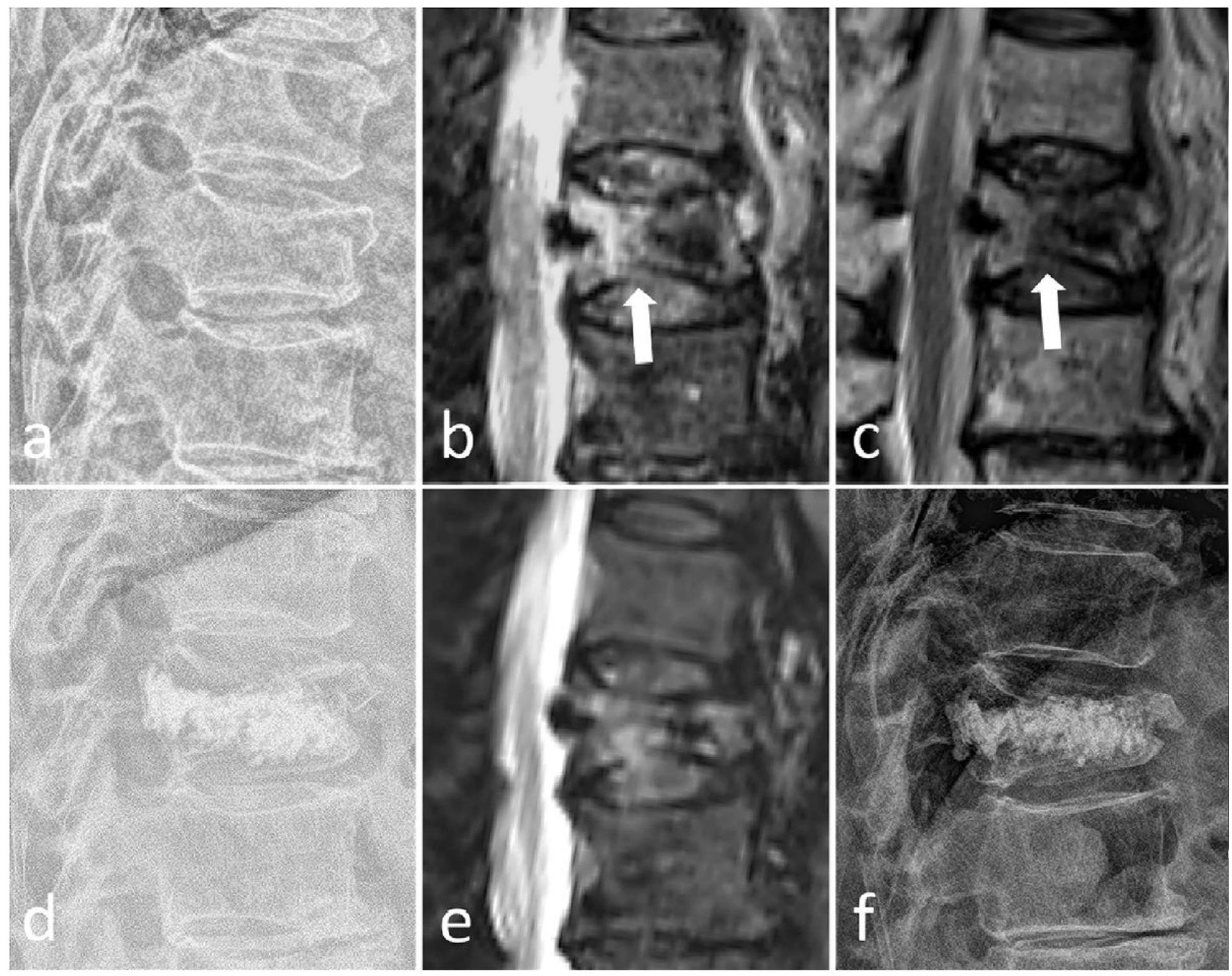

\section{Figure 4}

A, 85-year-old woman with refracture after PVP Preoperative lateral radiographs, STIR, and T2W images (a-c) showed a T12 compression fracture with endplate cortical disruption (black arrow). Postoperative lateral radiographs (d) after one day showed NPEC on the lower and upper endplates. The STIR image and lateral radiograph six months after PVP $(e, f)$ showed refracture of the cemented T12 vertebra with loss of height and bone marrow edema. 